\title{
Dietary sodium intake regulates angiotensin II type 1, mineralocorticoid receptor, and associated signaling proteins in heart
}

\author{
Vincent Ricchiuti, Nathalie Lapointe, Luminita Pojoga, Tham Yao, Loc Tran, Gordon H Williams \\ and Gail K Adler
}

Division of Endocrinology, Diabetes and Hypertension, Department of Medicine, Harvard Medical School, Brigham and Women's Hospital, 221 Longwood Avenue, Boston, Massachusetts 02115, USA

(Correspondence should be addressed to V Ricchiuti; Email: vricchiuti@partners.org)

\begin{abstract}
Liberal or high-sodium (HS) intake, in conjunction with an activated renin-angiotensin-aldosterone system, increases cardiovascular $(\mathrm{CV})$ damage. We tested the hypothesis that sodium intake regulates the type 1 angiotensin II receptor $\left(\mathrm{AT}_{1} \mathrm{R}\right)$, mineralocorticoid receptor (MR), and associated signaling pathways in heart tissue from healthy rodents. HS $\left(1 \cdot 6 \% \mathrm{Na}^{+}\right)$ and low-sodium (LS; $0 \cdot 02 \% \mathrm{Na}^{+}$) rat chow was fed to male healthy Wistar rats ( $n=7$ animals per group). Protein levels were assessed by western blot and immunoprecipitation analysis. Fractionation studies showed that $\mathrm{MR}, \mathrm{AT}_{1} \mathrm{R}$, caveolin-3 (CAV-3), and CAV-1 were located in both cytoplasmic and membrane fractions. In healthy rats, consumption of an LS versus a HS diet led to decreased cardiac levels of $\mathrm{AT}_{1} \mathrm{R}$ and MR. Decreased sodium intake was also associated with

decreased cardiac levels of CAV-1 and CAV-3, decreased immunoprecipitation of $\mathrm{AT}_{1} \mathrm{R}-\mathrm{CAV}-3$ and $\mathrm{MR}-\mathrm{CAV}-3$ complexes, but increased immunoprecipitation of $\mathrm{AT}_{1} \mathrm{R} / \mathrm{MR}$ complexes. Furthermore, decreased sodium intake was associated with decreased cardiac extracellular signal-regulated kinase (ERK), phosphorylated ERK (pERK), and pERK/ ERK ratio; increased cardiac striatin; decreased endothelial nitric oxide synthase (eNOS) and phosphorylated eNOS (peNOS), but increased peNOS/eNOS ratio; and decreased cardiac plasminogen activator inhibitor-1. Dietary sodium restriction has beneficial effects on the cardiac expression of factors associated with CV injury. These changes may play a role in the cardioprotective effects of dietary sodium restriction. Journal of Endocrinology (2011) 211, 47-54
\end{abstract}

\section{Introduction}

An extensive body of clinical and pre-clinical literature documents the adverse cardiovascular (CV) effects of angiotensin II (ANGII; Schmieder et al. 2007). Recent studies suggest that aldosterone or mineralocorticoid receptor (MR) activation is a major factor contributing to $\mathrm{CV}$ dysfunction and damage, either in combination with or in lieu of ANGII (Pitt et al. 1999, Rocha et al. 2002, Pitt et al. 2003, Marney \& Brown 2007, Benard et al. 2009, Garg \& Adler 2009). Dietary sodium intake is an important modulator of ANGII/aldosterone-induced CV damage. Multiple animal studies have demonstrated a decrease in ANGII/aldosterone-induced CV damage with sodium restriction, despite the increase in plasma renin activity (PRA), ANGII, and aldosterone. Furthermore, the decrease in CV injury is not mediated by decreases in blood pressure (BP; Rocha et al. 2000, Martinez et al. 2002, Johansson et al. 2009).

With the goal of further defining the effects of sodium intake on CV pathophysiology, we determined the effects of liberal or high-sodium (HS) and low-sodium (LS) diets on aldosterone and ANGII pathways in the hearts of healthy rodents. We examined the cardiac protein levels of receptors for ANGII and aldosterone and the protein levels of other factors that may modify the actions of these two hormones, specifically caveolins. Caveolae and their associated proteins (caveolins) and striatin, a caveolinassociated protein, were recently shown to mediate the non-genomic actions of steroids ( $\mathrm{Lu}$ et al. 2004) and to participate in activation of signaling transduction pathways of membrane receptors, including steroid receptors and type 1 angiotensin II receptor $\left(\mathrm{AT}_{1} \mathrm{R}\right.$; Ushio-Fukai et al. 2005, Zuo et al. 2005). We also assessed extracellular signal-regulated kinase (ERK) activity and plasminogen activator inhibitor-1 (PAI-1) as these factors are activated by both ANGII and aldosterone and have adverse effects on the heart (Oestreicher et al. 2003). Finally, the effects of sodium intake on cardiac endothelial nitric oxide synthase (eNOS) activity were assessed as NO has beneficial CV effects that could counter the adverse effects of ANGII/ aldosterone. Thus, the goal of this study was to test the hypothesis that dietary sodium restriction has beneficial effects on the heart by reducing cardiac expression of $\mathrm{AT}_{1} \mathrm{R}, \mathrm{MR}$, associated signaling transduction proteins, and inflammation. 


\section{Materials and Methods}

\section{Experimental animals}

The studies were conducted in accordance with Harvard Medical School institutional guidelines for the humane treatment of animals. Eight-week-old male Wistar rats, weighing 225-250 g, were obtained from Charles River Laboratories, Inc. (Wilmington, MA, USA). All animals were housed in a room lighted $12 \mathrm{~h} /$ day at an ambient temperature of $22 \pm 1^{\circ} \mathrm{C}$. Animals were allowed 1 week to recover after arrival and had free access to Purina Rat Chow 5001 (Ralston Purina Co., St Louis, MO, USA) and tap water until the initiation of the experiment. To assess the influence of dietary sodium restriction, rats were randomized to one of the two treatment groups: HS rat chow containing $1.6 \% \mathrm{Na}^{+}$or LS rat chow containing $0.02 \% \mathrm{Na}^{+}$for 6 days before the experiments.

\section{$B P$ measurements}

Systolic BP was assessed by tail-cuff plethysmography on day 6 , prior to the animals being killed as previously reported (Martinez et al. 2002, Oestreicher et al. 2003, Guo et al. 2006, Pajoga et al. 2010).

\section{Experimental procedures}

Western blot analysis Heart tissues were homogenized in $1 \mathrm{ml}$ ice-cold lysing solution (Bio-Rad Cell Lysis Kit - Cat \#171-304012). The ground tissue was transferred to a clean microcentrifuge tube and frozen at $-70{ }^{\circ} \mathrm{C}$. Homogenates were then thawed and sonicated on ice (Fisher Sonic Dismembrator, model 300, Fisher Scientific, Pittsburgh, PA, USA). Samples were then centrifuged at $3220 \boldsymbol{g}$ for $4 \mathrm{~min}$ at $4{ }^{\circ} \mathrm{C}$. Supernatant was collected without disturbing the pellets. Protein concentration in the supernatant was determined using modified Lowry assay (RC DC protein assay, Bio-Rad Cat \#500-0119, Bio-Rad). Supernatants (20 $\mu \mathrm{g}$ of protein concentration) were combined at least 1:2 with sample buffer $(62.5 \mathrm{mM}$ Tris, $\mathrm{pH} 6 \cdot 8,2 \%$ SDS, $25 \%$ glycerol, $0.01 \%$ bromophenol blue, and $200 \mathrm{mM}$ $\beta$-mercaptoethanol), heated at $95^{\circ} \mathrm{C}$ for $4 \mathrm{~min}$, and size fractionated by electrophoresis on $12.5 \%$ SDS-polyacrylamide gels using $1 \times$ of the following $10 \times$ buffer: $250 \mathrm{mM}$ Tris base, $1.92 \mathrm{M}$ glycine, and $34.7 \mathrm{mM}$ SDS. Proteins were electrophoretically transferred to Hybond enhanced chemiluminescence (ECL) nitrocellulose membranes (Amersham Biosciences) using the following transfer buffer: $25 \mathrm{mM}$ Tris, $192 \mathrm{mM}$ glycine, and 20\% v/v methanol, $\mathrm{pH} \mathrm{8.3.} \mathrm{The}$ membranes were blocked in 5\% non-fat dried milk in PBS-T ( $80 \mathrm{mM} \mathrm{Na}_{2} \mathrm{HPO}_{4}$ anhydrous, $20 \mathrm{mM} \mathrm{NaH} \mathrm{PO}_{4}, 100 \mathrm{mM}$ $\mathrm{NaCl}$, and $0 \cdot 1 \%$ Tween 20 ) for $1 \mathrm{~h}$ at room temperature on an orbital shaker. Primary antibody incubation was incubated overnight at $4{ }^{\circ} \mathrm{C}$ with antibody diluent consisting of $1 \%$ non-fat dried milk in PBS-T. Equal loading was assessed by reprobing membranes with an antibody to $\beta$-actin (Clone AC-15, Sigma 1:5000). After overnight incubation, the bound antibody was detected by ECL (Western Lightning Reagent Plus, Perkin Elmer Life Sciences, Boston, MA, USA) with HRP-conjugated goat anti-rat IgG (Cat \#sc-2006, Santa Cruz Biotechnology, Inc., Santa Cruz, CA, USA, dilution 1:3000) or goat anti-mouse IgG (Cat \#sc-2005, Santa Cruz Biotechnology, Inc., dilution 1:5000) or goat anti-rabbit IgG (Cat \#sc-2004, Santa Cruz Biotechnology, Inc., dilution 1:5000). Developed X-ray films were scanned and densitometric analysis was performed with the ImageQuant 5.2 Software (Molecular Dynamics, Piscataway, NJ, USA). To control for inter-gel variations, we used the following procedure. On each 15-well mini-gels, we analyzed three to four samples from each of the two treatment groups; two samples were used for normalization between mini-gels. All western blots were re-probed once with anti- $\beta$ actin antibody and the protein of interest was normalized to $\beta$-actin to correct for loading variability. Samples were re-analyzed on a separate western blot to confirm results. All values were expressed relative to $\beta$-actin levels.

\section{Preparation of membrane and cytoplasmic fractions} from heart tissues To separate the proteins from membrane and cytoplasmic fractions from heart tissues, we used the compartmental protein extraction kit from BioChain Institute, Inc. (Hayward, CA, USA) as described previously (Sharma-Walia et al. 2004). In brief, $1 \mathrm{~g}$ heart tissue was chopped into small pieces and then homogenized using buffer $\mathrm{C}$ (cytoplasmic) provided in the kit. The extraction was mixed gently at $4{ }^{\circ} \mathrm{C}$ for $20 \mathrm{~min}$ and then spun down at $18000 \mathrm{~g}$ at $4{ }^{\circ} \mathrm{C}$ for $20 \mathrm{~min}$. The cytoplasmic protein fractions (the supernatant) were removed and transferred into a clean tube. The pellet was re-suspended with cold buffer $\mathrm{C}$ on ice. The solution was mixed gently at $4{ }^{\circ} \mathrm{C}$ for $5 \mathrm{~min}$ and then centrifuged at $18000 \mathrm{~g}$ at $4^{\circ} \mathrm{C}$ for $20 \mathrm{~min}$. The supernatant was removed and the pellet was re-suspended with cold buffer $\mathrm{M}$ (membrane) provided in the kit. The solution was mixed gently at $4{ }^{\circ} \mathrm{C}$ for $20 \mathrm{~min}$ and centrifuged at $9000 \mathrm{~g}$ at $4{ }^{\circ} \mathrm{C}$ for $20 \mathrm{~min}$. The membrane proteins in the supernatant were transferred into a clean tube. Protein concentration in the cytoplasmic and membrane fractions was determined using modified Lowry assay (RC DC protein assay, Bio-Rad Cat \#500-0119, Bio-Rad). Proteins were stored at $-70{ }^{\circ} \mathrm{C}$ until western blot and immunoprecipitation analysis were performed.

Immunoprecipitation Proteins were extracted from heart tissues following western blot protein extraction procedure described above. Total protein extract $(250 \mu \mathrm{g})$ was incubated with 5-10 $\mu$ of antibody (amount of antibody used was according to manufacturer recommendations) in $1 \times$ RIPA buffer (Cat \#20-188, Upstate Cell Signaling Solutions, Temecula, CA, USA; $0 \cdot 5 \mathrm{M}$ Tris- $\mathrm{HCl}, \mathrm{pH} 7 \cdot 4$, $1.5 \mathrm{M} \mathrm{NaCl}, 2.5 \%$ deoxycholic acid, $10 \% \mathrm{NP}-40$, and $10 \mathrm{mM}$ EDTA). The mixture of protein extract and antibody was placed on rotator (model \#415110, Barnstead 


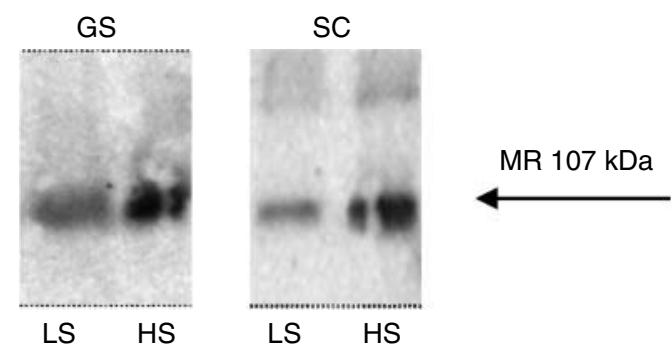

Figure 1 Representative western blots for MR from Dr GomezSanchez (GS) versus MR from Santa Cruz (SC) in rats on highsodium (HS) and low-sodium (LS) diets.

International) for $2 \mathrm{~h}$ at $4{ }^{\circ} \mathrm{C}$. Protein $\mathrm{A} / \mathrm{G}$ Plus agarose (20 $\mu \mathrm{l}$; Cat \#sc-2003, Santa Cruz Biotechnology, Inc.) was added into mixture and solution containing protein, antibody, and agarose agent was incubated over night at $4{ }^{\circ} \mathrm{C}$. Samples were centrifuged, and the pellet was washed four times in $1 \times$ RIPA buffer. The pellet was suspended in $40 \mu \mathrm{l}$ of loading buffer and $10 \mu \mathrm{l}$ were used for electrophoresis followed by western blot analysis as described above.

Antibodies We tested two anti-MR antibodies (Cat \#sc11412, Santa Cruz Biotechnology, Inc., dilution 1:1000 and one kindly provided by Gomez-Sanchez et al. (2006)) to determine which would be more useful on tissue extracts from hearts. As shown in Fig. 1, the ability of both antibodies to bind to MR in western blot is similar. Because the results were the same, we chose the Santa Cruz antibody because of its higher concentration.

In addition to the anti-MR, we used an antibody to $\mathrm{AT}_{1} \mathrm{R}$ (Cat \#sc-1173, Santa Cruz Biotechnology, Inc., dilution 1:1000) for western blot analysis. We previously demonstrated the specificity of the Santa Cruz $\mathrm{AT}_{1} \mathrm{R}$ antibody (sc-1173) by performing peptide competition studies with a blocking peptide specific to the sc-1173 antibody (Oestreicher et al. 2006). Furthermore, we demonstrated excellent correlation between western blot results using sc-1173 antibody and quantification of $\mathrm{AT}_{1} \mathrm{R}$ in tissue by radioligand binding with $\mathrm{I}^{125}$-labeled ANGII (Oestreicher et al. 2006). The following antibodies were also used: caveolin-1 (CAV-1; Cat\# RDICAVEOL1abrx, Research Diagnostics, Concord, MA, USA, dilution 1:5000), CAV-3 (Cat \#RDI-CAVEOL3abrx, Research Diagnostics, Concord, dilution 1:10 000), eNOS (Cat \#610298, BD Transduction Laboratories, San Jose, CA,
USA, dilution 1:2500), phosphorylated eNOS (peNOS; Cat \#9571S, Cell Signaling, Danvers, MA, USA, dilution 1:1000), PKC (Cat \#610107, BD Transduction Laboratories, dilution, 1:1000), PKC $\delta$ (Cat \#610397 BD Transduction Laboratories, dilution 1:1000), ERK1/2 (Cat \#4696, Cell Signaling, dilution 1:2000), phosphorylated ERK1/2 (pERK1/2; Cat \#9101S, Cell Signaling, dilution 1:2000), PAI-1 (Cat \#612024, BD Transduction Laboratories, dilution 1:2500), striatin (Cat \#AB5779, Millipore, Billerica, MA, USA, dilution 1:500), $\beta$-actin (Cat \#A1978, Sigma-Aldrich, dilution 1:5000), GAPDH (Cat \#AB9482, Abcam, dilution 1:5000), and Cadherin (Cat \#AB6529, Abcam, dilution 1:200).

Assays and analyses Plasma aldosterone was measured with DPC Coat-A-Count RIA (DPC Diagnostic Products, Los Angeles, CA, USA). Urinary aldosterone obtained from a $24 \mathrm{~h}$ sample collection was extracted and quantified using aldosterone DPC Coat-A-Count. The PRA determination involved an initial incubation of plasma to generate angiotensin I, followed by quantitation by RIA (DiaSorin, Stillwater, $\mathrm{MN}$, USA). Urine sodium $\left(\mathrm{Na}^{+}\right)$and potassium $\left(\mathrm{K}^{+}\right)$were measured by ion-selective electrodes (Roche Diagnostics). Urine creatinine $(\mathrm{Cr})$ was measured by buffered kinetic Jaffé reaction without deproteinization (Roche Diagnostics).

\section{Statistical analysis}

The statistical significance of the differences between group means for the data were determined by two-sided $t$-tests using ABI Prism Software (Applied Biosystems Corporation, Foster City, CA, USA). Differences in means with $P$ values $\leq 0.05$ were considered statistically significant. Values are expressed as mean \pm s.E.M.

\section{Results}

Effect of dietary sodium on the renin-angiotensin-aldosterone system

Rodents receiving a LS diet (similar to a severely restricted sodium intake in humans - $10 \mathrm{mmol} /$ day), compared with a HS diet (similar to a moderately HS intake in humans $250 \mathrm{mmol} /$ day; Rogacz et al. 1987), had lower sodium to $\mathrm{Cr}$ ratio in a $24 \mathrm{~h}$ urine collection and an activated renin-angiotensin-aldosterone system (RAAS; Table 1).

Table 1 Effects of sodium diets on urinary and plasma aldosterone and plasma renin activity (PRA) levels

\begin{tabular}{|c|c|c|c|c|c|c|c|}
\hline \multirow[b]{2}{*}{$\begin{array}{l}\text { Rat treatment } \\
\text { group }\end{array}$} & \multirow[b]{2}{*}{$n$} & \multirow[b]{2}{*}{$\mathbf{B P}(\mathrm{mmHg})$} & \multicolumn{3}{|l|}{$24 \mathrm{~h}$ urine } & \multicolumn{2}{|l|}{ Plasma } \\
\hline & & & $\begin{array}{l}\mathrm{Na}^{+} / \mathrm{Cr} \\
(\mathrm{mEq} / \mathrm{mg})\end{array}$ & $\begin{array}{l}\mathrm{K}^{+} / \mathrm{Cr} \\
(\mathrm{mEq} / \mathrm{mg})\end{array}$ & $\begin{array}{l}\text { Aldosterone/Cr } \\
(\mathrm{ng} / \mathrm{g})\end{array}$ & $\begin{array}{l}\text { Aldosterone } \\
(\mathrm{ng} / \mathrm{dl})\end{array}$ & $\begin{array}{l}\text { PRA } \\
(\mathrm{ng} / \mathrm{ml} \text { per h) }\end{array}$ \\
\hline $0.02 \% \mathrm{Na}^{+}$ & 7 & $114 \cdot 7 \pm 8 \cdot 1^{*}$ & $0.03 \pm 0.01^{\dagger}$ & $0 \cdot 41 \pm 0 \cdot 01$ & $52 \cdot 44 \pm 10 \cdot 09 *$ & $17 \cdot 55 \pm 2 \cdot 12^{*}$ & $14 \cdot 77 \pm 3 \cdot 39 *$ \\
\hline
\end{tabular}

$* P \leq 0 \cdot 05$ for $\mathrm{HS}$ versus $\mathrm{LS} ;{ }^{+} P \leq 0 \cdot 01$ for $\mathrm{HS}$ versus $\mathrm{LS}$. 
Specifically, PRA levels were increased more than twofold and plasma and urine aldosterone levels were increased three- to five-fold (Table 1). Our results showed that systolic BP was about $5 \mathrm{mmHg}$ lower on the LS versus HS diet (Table 1).

\section{Effect of sodium intake on $A T_{1} R$ and $M R$ in rat heart}

Cardiac levels of $\mathrm{AT}_{1} \mathrm{R}$ and $\mathrm{MR}$ protein were decreased in rats on LS compared to HS diet (Fig. 2A and B): a 10.6-fold decrease for $\mathrm{AT}_{1} \mathrm{R}$ and $2 \cdot 4$-fold decrease for $\mathrm{MR}$. No change was observed in $\beta$-actin expression (Fig. 2C). A LS intake also led to decreases in CAV-1 and CAV-3 (Fig. 2D and E); however, levels of an early transduction pathway protein, striatin, were increased (Fig. 2F). Immunoprecipitation studies using antibodies to $\mathrm{AT}_{1} \mathrm{R}$ or $\mathrm{MR}$ resulted in immunoprecipitation of CAV-3, suggesting an association of CAV-3 with both $\mathrm{AT}_{1} \mathrm{R}$ and $\mathrm{MR}$; these associations were reduced in animals receiving a LS diet (Fig. $2 \mathrm{G}$ and $\mathrm{H}$ ). Immunoprecipitation studies also showed an association of $\mathrm{AT}_{1} \mathrm{R}$ with MR. Despite the reduction in protein levels of cardiac $\mathrm{AT}_{1} \mathrm{R}$ and $\mathrm{MR}$, there was an increase in $\mathrm{AT}_{1} \mathrm{R} / \mathrm{MR}$ association with dietary sodium restriction (Fig. 2I).

\section{Effect of sodium intake on signaling molecules}

Cardiac levels of ERK and pERK were decreased under LS condition when compared with a liberal sodium intake
(Fig. 3A and B). Furthermore, the ratio of pERK to ERK was reduced with LS diet (Fig. 3C), suggesting that there is a decrease in the efficiency of ERK phosphorylation as well as a decrease in overall protein levels. Similarly, other components of the ERK pathway, e.g. cardiac levels of PKC $\delta$ and total PKC, were reduced under the LS condition (Fig. 3D-F). LS diet was also associated with a decrease in cardiac levels of eNOS and peNOS (Fig. 4A and B). However, the ratio of peNOS to eNOS was increased (Fig. 4C), suggesting a potential increase in the efficiency of eNOS activation with dietary sodium restriction.

\section{Effect of sodium intake on PAI-1}

Levels of the prothrombotic factor PAI-1 were reduced in hearts of rodents on LS compared with HS diets (Fig. 4D).

Interaction between $A T_{1} R, M R, C A V-1$, and $C A V-3$ in cytosol versus membrane

We performed additional studies to address the interaction between $\mathrm{MR}, \mathrm{AT}_{1} \mathrm{R}, \mathrm{CAV}-3$, and $\mathrm{CAV}-1$ in the membrane versus the cytoplasmic fractions. We used GAPDH to assess the purity of our membrane fraction and cadherin to assess the purity of the cytoplasmic fraction. As can be seen in Fig. 5A and B, both preparations were free of contamination by the other fraction. Our results showed that $\mathrm{MR}, \mathrm{AT}_{1} \mathrm{R}$, CAV-1, and CAV-3 are all located in both fractions
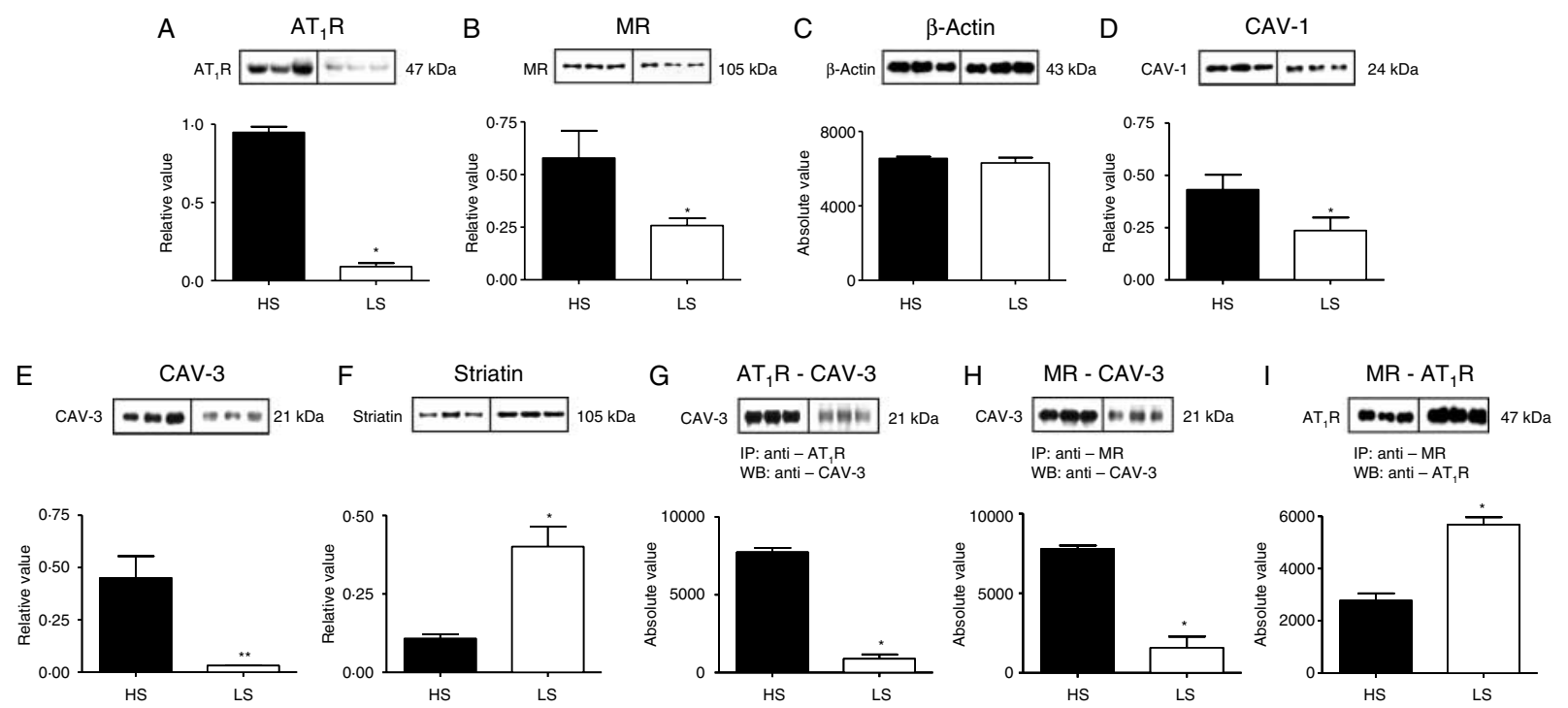

Figure 2 Low-sodium diet reduced cardiac $A T_{1} R, M R$, and caveolins but increased cardiac striatin and modulated interactions of $A T_{1} R$, $M R$, and CAV- 3 in heart cardiac levels of $A T_{1} R(A), M R(B)$, and $\beta$-actin $(C)$ in rats on high-sodium (HS, black bars) and low-sodium (LS, open bars) diets. Cardiac levels of CAV-1 (D), CAV-3 (E), and striatin (F) in rats on HS (black bars) and LS (open bars) diets. AT 1 R, MR, CAV-1, and CAV-3 and striatin levels are expressed relative to $\beta$-actin levels (relative value). Co-immunoprecipitation studies were performed on cardiac extracts from rats on HS (black bars) and LS (open bars) diets. Extracts underwent immunoprecipitation (IP) with antibodies to $\mathrm{AT}_{1} \mathrm{R}$ (G) or MR ( $\mathrm{H}$ and I) followed by western blot analysis (WB) using antibodies to CAV-3 (G and H) or AT $\mathrm{R}(\mathrm{I})$. Graphs show the results of the densitometric quantification of the $\mathrm{AT}_{1} \mathrm{R}-\mathrm{CAV}-3$ complex $(\mathrm{G}), \mathrm{MR}-\mathrm{CAV}-3$ complex $(\mathrm{H})$, and $\mathrm{MR}-\mathrm{AT}_{1} \mathrm{R}$ complex (I). Representative western blots for three animals on HS (left lanes) and three animals on LS (right lanes) diets are shown above each graph. $n=7$ per group. ${ }^{*} P<0 \cdot 05$ and $* * P<0 \cdot 01$. 
A
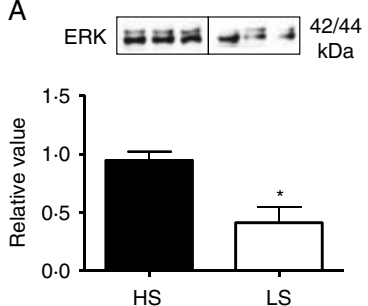

C

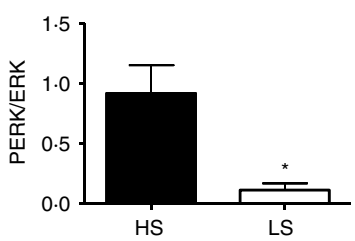

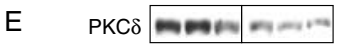

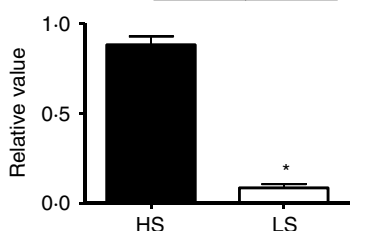

B PERK \begin{tabular}{|c|c|c|c|c|}
$42 / 44$ \\
$\mathrm{kDa}$
\end{tabular}

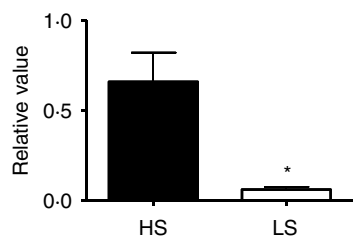

D Total PKC $\leadsto$

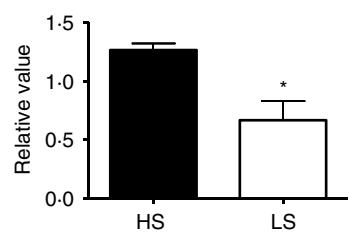

$\mathrm{F}$

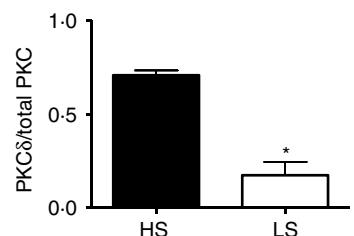

Figure 3 LS diet reduced cardiac levels of ERK, pERK, total PKC, PKC $\delta$, the ratio of $\mathrm{pERK/ERK}$, and the ratio of $\mathrm{PKC} \delta /$ total PKC. Cardiac levels of ERK (A), pERK (B), and the ratio of pERK/ERK (C) in rats on HS (black bars) and LS (open bars) diets. Cardiac levels of total PKC (D), PKC $\delta(E)$, and the ratio of PKC $\delta$ /total PKC (F) in rats on HS (black bars) and LS (open bars) diets. ERK, pERK, total PKC, and $\mathrm{PKC} \delta$ are expressed relative to $\beta$-actin levels (relative value). Representative western blots for 3 animals on HS (left lanes) and 3 animals on LS (right lanes) diets are shown above the graph. $n=7$ per group. ${ }^{*} P<0 \cdot 05$.

(Fig. 5A and B). The approach used does not allow a quantitative assessment of their relative abundance in each fraction. Immunoprecipitation studies demonstrate a strong interaction between $M R$ and $\mathrm{AT}_{1} \mathrm{R}$ as well as $\mathrm{MR}$ and CAV-3 in both the cytoplasmic and the membrane fractions. Importantly (and serving as negative controls), MR does not co-precipitate with either GAPDH in the cytoplasmic fraction or cadherin in the membrane fraction. Thus, the change in co-precipitation of $\mathrm{MR}-\mathrm{AT}_{1} \mathrm{R}$ levels between liberal and low-salt intakes in Fig. 2I could be occurring either in the membrane or cytosol or both.

\section{Discussion}

This study demonstrates that dietary sodium restriction reduces cardiac levels of proteins associated with $\mathrm{CV}$ injury (MR, $\mathrm{AT}_{1} \mathrm{R}, \mathrm{pERK}$, and PAI-1) in rodents. Since $\mathrm{AT}_{1} \mathrm{R}$ and $M R$ are known to activate the ERK signaling pathway, it is likely that the decrease in cardiac $\mathrm{AT}_{1} \mathrm{R}$ and $\mathrm{MR}$ and/or the

increase in association of $\mathrm{AT}_{1} \mathrm{R}$ and $\mathrm{MR}$ lead to decreased ERK pathway signaling in rodents consuming an LS diet.

LS intake, which increases circulating levels of the RAAS, is associated with decreased levels of $\mathrm{AT}_{1} \mathrm{R}$ in vessels and adrenal glomerulosa (Williams et al. 1976, Aguilera \& Catt 1981, Bellucci \& Wilkes 1984). The decreases in $\mathrm{AT}_{1} \mathrm{R}$ have been attributed to downregulation of $\mathrm{AT}_{1} \mathrm{R}$ by the elevated ANGII levels associated with dietary sodium restriction - the classic ligand/receptor relationship (Williams et al. 1976, Aguilera et al. 1981, Bellucci \& Wilkes 1984). Our results, demonstrating a decrease in cardiac $\mathrm{AT}_{1} \mathrm{R}$ and $\mathrm{MR}$ in rodents on a LS diet, are consistent with a similar process occurring in the heart. However, other investigators have suggested that tissue RAAS activity is regulated independently of circulating RAAS (Dzau 1987, Bader et al. 2001). Additional possible mechanistic explanations for the dietary-induced changes in cardiac $\mathrm{AT}_{1} \mathrm{R}$ and $\mathrm{MR}$ include changes in cardiac filling or BP. Though we did not assess the effect of dietary sodium on cardiac filling in our study, other investigators (Doi et al. 2000) have demonstrated that a very high $3 \cdot 2 \%$ sodium $(8 \% \mathrm{NaCl})$ diet for 6 weeks did not alter left ventricular diastolic filling compared to rodents on a low $0 \cdot 12 \%$ sodium $(0 \cdot 3 \% \mathrm{NaCl})$ diet. Twelve weeks of the $3 \cdot 2 \%$ sodium diet did induce changes. Since the liberal sodium diet in the current study was $1.6 \%$ sodium for only 6 days, it is unlikely that changes in cardiac filling led to changes in cardiac $\mathrm{AT}_{1} \mathrm{R}$ and $\mathrm{MR}$. In our study paradigm, mean systolic BP was $4.7 \mathrm{mmHg}$ higher in mice on the liberal sodium versus LS diet; cardiac $\mathrm{AT}_{1} \mathrm{R}$ levels were increased about tenfold and MR levels 2·4-fold. While we consider it unlikely, we cannot exclude the possibility that this change in $\mathrm{BP}$, within the normotensive
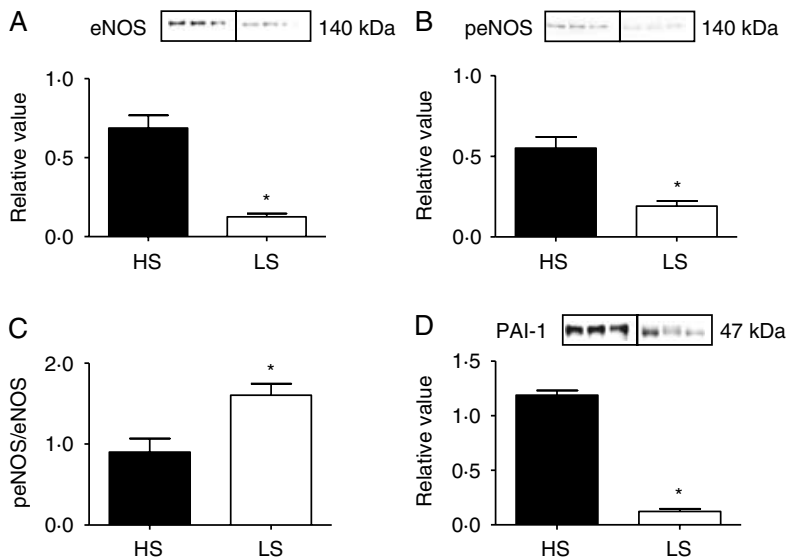

Figure 4 LS diet reduced cardiac levels of eNOS, peNOS, and PAI-1 but increased ratio of peNOS/eNOS. Cardiac levels of eNOS (A), peNOS (B), and the ratio of peNOS/eNOS (C) in rats on HS (black bars) and LS (open bars) diets. Cardiac levels of PAI-1 (D) in rats on HS (black bars) and LS (open bars) diets. eNOS, peNOS, and PAI-1 are expressed relative to $\beta$-actin levels (relative value). Representative western blots for 3 animals on HS (left lanes) and 3 animals on LS (right lanes) diets are shown above the graph. $n=7$ per group. ${ }^{*} P<0 \cdot 05$. 


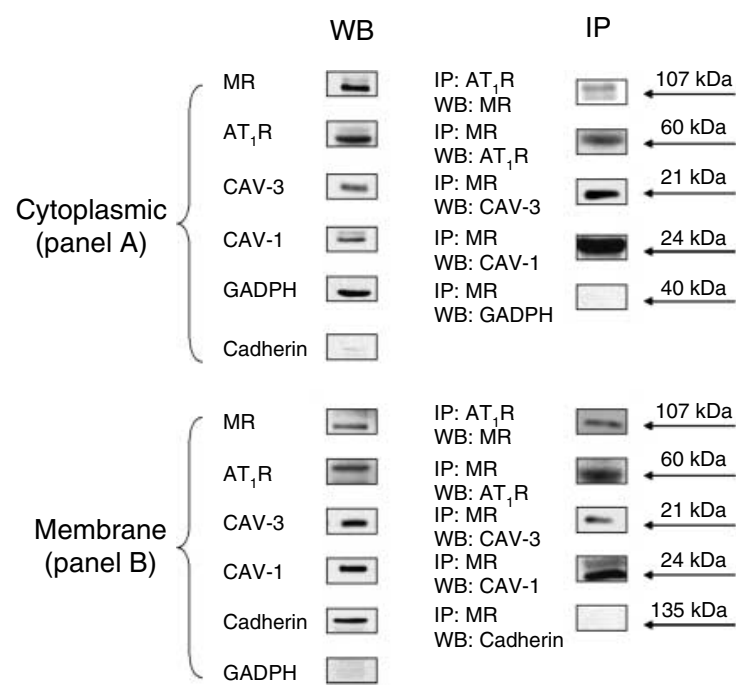

Figure 5 Location of $A T_{1} R, M R, C A V-1$, and $C A V-3$ proteins in cytosol versus membrane fractions and interaction with MR in heart tissue. $\mathrm{AT}_{1} \mathrm{R}, \mathrm{MR}, \mathrm{CAV}-1$, and $\mathrm{CAV}-3$ proteins detected by western blot (WB) and immunoprecipitation (IP) studies between MR and $\mathrm{AT}_{1} \mathrm{R}$ and between MR and CAV-3 in cytoplasmic fraction (panel A) and membrane fraction (panel B). Specific markers for cytoplasmic (GAPDH) and membrane (cadherin) fractions were used to assess the purity of the fractions and specificity of IP method.

range for 6 days, contributed to the observed changes in cardiac $\mathrm{AT}_{1} \mathrm{R}$ and $\mathrm{MR}$.

If, as we propose, ANGII downregulates the cardiac $\mathrm{AT}_{1} \mathrm{R}$, this raises the question as to how ANGII infusions induce cardiac injury in rodents on HS diet (Rocha et al. 2002). It is likely that in animals on a high or average salt intake, the presence of CV damage in ANGII-infused animals reflects an inability of the infused ANGII to appropriately downregulate the $\mathrm{AT}_{1} \mathrm{R}$. Potentially, there are tissue-specific factors and/or additional dietary sodium-associated factors that affect $\mathrm{AT}_{1} \mathrm{R}$ levels and/or other mediators of CV risk. In contrast, on the low-salt diet, where the dietary condition per se has already downregulated the receptor, the addition of infused ANGII does not cause CV damage (Aguilera \& Catt 1981) potentially because there is no imbalance between the ANGII level and the level of the $A_{1} \mathrm{R}$. However, the LS diet may have additional protective effects, e.g. decreased MR, pERK and PAI-1, and increased peNOS/eNOS ratio.

The decrease in ERK phosphorylation in hearts of rats on a LS diet may have been secondary to the reduction in cardiac $\mathrm{AT}_{1} \mathrm{R}$ and $\mathrm{MR}$ as activation of these receptors leads to ERK phosphorylation (Marney \& Brown 2007). In addition, the increase in the association of $\mathrm{AT}_{1} \mathrm{R}$ and $\mathrm{MR}$ may impair signaling through either $\mathrm{AT}_{1} \mathrm{R}$ or $\mathrm{MR}$ and thus contribute to a decrease in ERK pathway signaling with dietary sodium restriction. Furthermore, decreases in cardiac PAI-1 with dietary sodium restriction are a likely reflection of the decreases in cardiac $A T_{1} R, M R$, and $p E R K$, since $A T_{1} R$, $M R$, and ERK pathway activation all increase PAI-1 (Marney $\&$ Brown 2007). Thus, our studies suggest that dietary sodium restriction has beneficial cardiac effects despite the elevation in systemic ANGII and aldosterone. These changes in cardiac $\mathrm{AT}_{1} \mathrm{R}$ and MR may provide one mechanism for the decrease in myocardial necrosis, inflammation, and fibrosis with dietary sodium restriction in animal models of aldosterone-mediated CV injury (Rocha et al. 2000, Garg \& Adler 2009). In future studies, it would be useful to ascertain the long-term relationship between different dietary sodium intakes and expression of cardiac $\mathrm{AT}_{1} \mathrm{R}$ and MR. Given the key roles $\mathrm{AT}_{1} \mathrm{R}$ and MR play in the pathophysiology of CV disease, understanding these effects of dietary sodium would be particularly relevant in models of $\mathrm{CV}$ disease, e.g. hypertension and heart failure, where inappropriate regulation of cardiac $\mathrm{AT}_{1} \mathrm{R}$ and $\mathrm{MR}$ potentially could have adverse CV effects.

Studies with another steroid receptor, the estrogen receptor $\alpha(E R \alpha)$, have demonstrated interactions between CAV-1 and $\mathrm{ER} \alpha$ and the association of $\mathrm{ER} \alpha$ with caveolae, invaginated domains of plasma membrane that contain multiple signaling proteins (Klinge et al. 2008). Activation of the ER $\alpha-\mathrm{eNOS}$ membrane-signaling complex within caveolae leads to rapid activation of downstream pathways including eNOS (Chambliss et al. 2000). As occurs with ER $\alpha$, we found an association between both CAV-1 and CAV- 3 and the MR. Furthermore, we demonstrated interactions between CAV-3 and $\mathrm{AT}_{1} \mathrm{R}$, as has been reported (Ushio-Fukai \& Alexander 2006), and between $M R$ and $A T_{1} R$. Both $A T_{1} R$ and $M R$ were located in the membrane and cytoplasmic fractions, and immunoprecipitation studies revealed strong interactions between $M R$ and $A T_{1} R$ in both fractions. These results suggest that the change in co-precipitation of $\mathrm{AT}_{1} \mathrm{R}$ and MR when sodium intake was restricted is likely to be occurring in both fractions.

The increased ratio of peNOS to eNOS in hearts of rodents on an LS diet suggests an increased efficiency in the conversion of eNOS to peNOS, which could have beneficial cardiac effects given the key role of peNOS in the generation of the vasodilator NO. However, the overall reduction in total and peNOS with LS diet raises some questions as to the benefit of LS diet on the cardiac eNOS system. While the mechanism for the increase in peNOS to eNOS ratio was not established, dietary sodium restriction decreased cardiac caveolins and increased cardiac striatin, a protein that associates with both CAV-1 and ER $\alpha$. Decreases in CAV-1 and increases in striatin are linked to increases in ER activation of eNOS and increased NO production ( $\mathrm{Lu}$ et al. 2004). The ability of sodium intake to modulate cardiac caveolins in this study in rats confirms a previous report in mice (Pojoga et al. 2010). However, in contrast to these studies, there was no significant effect of sodium restriction in mice on phosphorylation of eNOS (Pojoga et al. 2010), perhaps reflecting differences in the experimental procedures between the current and previous study or differences in the responses to sodium restriction between mice and rats. Because caveolins and caveolae play a key role in signaling by multiple receptors, it is quite possible that dietary-induced 
changes in caveolae-associated proteins could affect multiple signaling pathways in addition to those involving $\mathrm{AT}_{1} \mathrm{R}$ and MR.

One of the limitations of the study was that the limited amount of heart tissue led us to choose to focus on markers that were previously shown in our group to be involved in molecular pathways of adverse CV events (Ricchiuti et al. 2009). We did not examine the effect of dietary sodium on cardiomyocyte hypertrophy or cardiac fibrosis. Additional studies are needed to determine whether dietary sodium affects these parameters or the activity of other pathways involved in cardiac protection and injury and to determine the applicability of our findings in rats to human physiology.

In conclusion, dietary sodium restriction produces substantial beneficial effects on the cardiac expression of factors associated with $\mathrm{CV}$ injury, reducing pathways involved in cardiac injury (MR, $\mathrm{AT}_{1} \mathrm{R}, \mathrm{ERK}$, and PAI-1) and potentially stimulating cardioprotective mechanisms (via NO pathways). These changes may play a role in the cardioprotective effects of dietary sodium restriction and could provide entrée to the assessment of ways to pharmacologically mimic the effects of sodium restriction to reduce $\mathrm{CV}$ risk in humans.

\section{Declaration of interest}

The authors declare that there is no conflict of interest that could be perceived as prejudicing the impartiality of the research reported.

\section{Funding}

This work was supported by NIH training grants 5T32HL007609 and DK07529 and NIH research grants HL-63423, HL-069208, HL-67332K24, and HL-07718.

\section{References}

Aguilera G \& Catt K 1981 Regulation of vascular angiotensin II receptors in the rat during altered sodium intake. Circulation Research 49 751-758.

Aguilera G, Harwood JP \& Catt KJ 1981 Somatostatin modulates effects of angiotensin II in adrenal glomerulosa zone. Nature 292 262-263. (doi:10.1038/292262a0)

Bader M, Peters J, Baltatu O, Müller DN, Luft FC \& Ganten D 2001 Tissue renin-angiotensin systems: new insights from experimental animal models in hypertension research. Journal of Molecular Medicine 79 76-102. (doi:10.1007/s001090100210)

Bellucci A \& Wilkes BM 1984 Mechanism of sodium modulation of glomerular angiotensin receptors in the rat. Journal of Clinical Investigation 74 1593-1600. (doi:10.1172/JCI111575)

Benard L, Milliez P, Ambroisine M, Messaoudi S, Samuel J \& Delcayre C 2009 Effects of aldosterone on coronary function. Pharmacological Reports $6158-66$.

Chambliss KL, Yuhanna IS, Mineo C, Liu P, German Z, Sherman TS, Mendelsohn ME, Anderson RG \& Shaul PW 2000 Estrogen receptor alpha and endothelial nitric oxide synthase are organized into a functional signaling module in caveolae. Circulation Research 87 e44.

Doi R, Masuyama T, Yamamoto K, Doi Y, Mano T, Sakata Y, Ono K, Kuzuya T, Hirota S, Koyama T et al. 2000 Development of different phenotypes of hypertensive heart failure: systolic versus diastolic failure in dahl saltsensitive rats. Journal of Hypertension 18 111-120. (doi:10.1097/00004872200018010-00016)

Dzau VJ 1987 Implications of local angiotensin production in cardiovascular physiology and pharmacology. American Journal of Cardiology 59 59A-65A. (doi:10.1016/0002-9149(87)90178-0)

Garg R \& Adler GK 2009 Aldosterone and its cardiovascular effects. In Textbook of Nephro-Endocrinology. Eds AK Singh \& GH Williams. Elsevier Science Publishers.

Gomez-Sanchez CE, de Rodriguez AF, Romero DG, Estess J, Warden MP, Gomez-Sanchez MT \& Gomez-Sanchez EP 2006 Development of a panel of monoclonal antibodies against the mineralocorticoid receptor. Endocrinology 147 1343-1348. (doi:10.1210/en.2005-0860)

Guo C, Martinez-Vasquez D, Mendez GP, Toniolo MF, Yao TM, Oestreicher EM, Kikuchi T, Lapointe N, Pojoga L, Williams GH et al. 2006 Mineralocorticoid receptor antagonist reduces renal injury in rodent models of types 1 and 2 diabetes mellitus. Endocrinology 147 5363-5373. (doi:10.1210/en.2006-0944)

Johansson ME, Bernberg E, Andersson IJ, Bie P, Skøtt O, Gan LM \& Bergström G 2009 High-salt diet combined with elevated angiotensin II accelerates atherosclerosis in apolipoprotein E-deficient mice. Journal of Hypertension 27 41-47. (doi:10.1097/HJH.0b013e328318697b)

Klinge CM, Wickramasinghe NS, Ivanova MM \& Dougherty SM 2008 Resveratrol stimulates nitric oxide production by increasing estrogen receptor alpha-Src-caveolin-1 interaction and phosphorylation in human umbilical vein endothelial cells. FASEB Journal 22 2185-2197. (doi:10.1096/fj.07-103366)

Lu Q, Pallas DC, Surks HK, Baur WE, Mendelsohn ME \& Karas RH 2004 Striatin assembles a membrane signaling complex necessary for rapid, nongenomic activation of endothelial NO synthase by estrogen receptor alpha. PNAS 101 17126-17131. (doi:10.1073/pnas.0407492101)

Pojoga LH, Romero JR, Yao TM, Loutraris P, Ricchiuti V, Coutinho P, Guo C, Lapointe N, Stone JR, Adler GK et al. 2010 Caveolin-1 ablation reduces the adverse cardiovascular effects of $\mathrm{N}$-omega-nitro-L-arginine methyl ester and angiotensin II. Endocrinology 151 1236-1246. (doi:10. 1210/en.2009-0514)

Marney AM \& Brown NJ 2007 Aldosterone and end-organ damage. Clinical Science 113 267-278. (doi:10.1042/CS20070123)

Martinez DV, Rocha R, Matsumura M, Oestreicher E, Ochoa-Maya M, Roubsanthisuk W, Williams GH \& Adler GK 2002 Cardiac damage prevention by eplerenone: comparison with low sodium diet or potassium loading. Hypertension 39 614-618.

Oestreicher EM, Martinez-Vasquez D, Stone JR, Jonasson L, Roubsanthisuk W, Mukasa K \& Adler GK 2003 Aldosterone and not plasminogen activator inhibitor-1 is a critical mediator of early angiotensin II/ NG-nitro-L-arginine methyl ester-induced myocardial injury. Circulation 108 2517-2523. (doi:10.1161/01.CIR.0000097000.51723.6F)

Oestreicher EM, Guo C, Seely EW, Kikuchi T, Martinez-Vasquez D, Jonasson L, Yao T, Burr D, Mayoral S, Roubsanthisuk W et al. 2006 Estradiol increases proteinuria and angiotensin II type 1 receptor in kidneys of rats receiving L-NAME and angiotensin II. Kidney International 70 1759-1768. (doi:10.1038/sj.ki.5001897)

Pitt B, Zannad F, Remme WJ, Cody R, Castaigne A, Perez A, Palensky J \& Wittes J 1999 The effect of spironolactone on morbidity and mortality in patients with severe heart failure. Randomized Aldactone Evaluation Study Investigators. New England Journal of Medicine 341 709-717. (doi:10.1056/ NEJM199909023411001)

Pitt B, Remme W, Zannad F, Neaton J, Martinez F, Roniker B, Bittman R, Hurley S, Kleiman J \& Gatlin M 2003 Eplerenone, a selective aldosterone blocker, in patients with left ventricular dysfunction after myocardial infarction. New England Journal of Medicine 348 1309-1321. (doi:10.1056/ NEJMoa030207)

Pojoga LH, Adamová Z, Kumar A, Stennett AK, Romero JR, Adler GK, Williams GH \& Khalil RA 2010 Sensitivity of NOS-dependent vascular relaxation pathway to mineralocorticoid receptor blockade in caveolin1-deficient mice. American Journal of Physiology. Heart and Circulatory Physiology 298 H1776-H1788. (doi:10.1152/ajpheart.00661.2009) 
Ricchiuti V, Lian CG, Oestreicher EM, Tran L, Stone JR, Yao T, Seely EW, Williams GH \& Adler GK 2009 Estradiol increases angiotensin II type 1 receptor in hearts of ovariectomized rats. Journal of Endocrinology 200 75-84. (doi:10.1677/JOE-08-0199)

Rocha R, Stier CT Jr, Kifor I, Ochoa-Maya MR, Rennke HG, Williams GH \& Adler GK 2000 Aldosterone: a mediator of myocardial necrosis and renal arteriopathy. Endocrinology 141 3871-3878. (doi:10.1210/en. 141.10.3871)

Rocha R, Martin-Berger CL, Yang P, Scherrer R, Delyani J \& McMahon E 2002 Selective aldosterone blockade prevents angiotensin II/salt-induced vascular inflammation in the rat heart. Endocrinology 143 4828-4836. (doi:10.1210/en.2002-220120)

Rogacz S, Hollenberg NK \& Williams GH 1987 Role of angiotensin II in the hormonal, renal, and electrolyte response to sodium restriction. Hypertension 9 289-294.

Schmieder ER, Hilgers FK, Schlaich PM \& Schmidt MWB 2007 Renin-angiotensin system and cardiovascular risk. Lancet 369 1208-1219. (doi:10.1016/S0140-6736(07)60242-6)

Sharma-Walia N, Naranatt PP, Krishnan HH, Zeng L \& Chandran B 2004 Kaposi's sarcoma-associated herpesvirus/human herpesvirus 8 envelope glycoprotein $\mathrm{gB}$ induces the integrin-dependent focal adhesion kinase-Src-phosphatidylinositol 3-kinase-rho GTPase signal pathways and cytoskeletal rearrangements. Journal of Virology $\mathbf{7 8} 4207-4223$ (doi:10.1128/JVI.78.8.4207-4223.2004)
Ushio-Fukai M \& Alexander RW 2006 Caveolin-dependent angiotensin II type 1 receptor signaling in vascular smooth muscle. Hypertension $\mathbf{4 8}$ 797-803. (doi:10.1161/01.HYP.0000242907.70697.5d)

Ushio-Fukai M, Zuo L, Ikeda S, Tojo T, Patrushev NA \& Alexander RW 2005 cAbl tyrosine kinase mediates reactive oxygen species- and caveolindependent AT1 receptor signaling in vascular smooth muscle: role in vascular hypertrophy. Circulation Research 97 829-836. (doi:10.1161/01. RES.0000185322.46009.F5)

Williams GH, Hollenberg NK \& Braley LM 1976 Influence of sodium intake on vascular and adrenal angiotensin II receptors. Endocrinology 98 1343-1350. (doi:10.1210/endo-98-6-1343)

Zuo L, Ushio-Fukai M, Ikeda S, Hilenski L, Patrushev N \& Alexander RW 2005 Caveolin-1 is essential for activation of Rac1 and NAD(P)H oxidase after angiotensin II type 1 receptor stimulation in vascular smooth muscle cells: role in redox signaling and vascular hypertrophy. Arteriosclerosis, Thrombosis, and Vascular Biology 25 1824-1830. (doi:10.1161/01.ATV. $0000175295.09607 .18)$

Received in final form 1 July 2011

Accepted 11 July 2011

Made available online as an Accepted Preprint 11 July 2011 